\title{
LIMITES NO ESPAÇO-TEMPO: A RETOMADA DE UM DEBATE
}

\author{
Rogerio Haesbaert \\ Universidade Federal Fluminense
}

\begin{abstract}
Resumo
Este artigo propõe-se a analisar um dos elementos constituintes mais importantes do território, o de seus limites ou 'fronteiras'. Partindo do debate sobre a relação indissociável entre espaço e tempo, considera os limites através de sua contextualização espaçotemporal e sem que eles sejam interpretados, a priori, como negativos, pois nossa existência e nossa autonomia dependem, constantemente, da imbricação entre abertura e fechamento, fixação e mobilidade, ou seja, criação e destruição de limites.
\end{abstract}

Palavras-chave: limite; fronteira; espaço; tempo.

\begin{abstract}
This article proposes to investigate one of the most important constituent elements of territory, its boundaries or 'frontiers'. We begin from the debate on the inextricably relationship between space and time, by focusing on the boundaries through its space-time contextualization. These boundaries are not interpreted, a priori, from a negative point of view, since our existence and our autonomy depend constantly on the overlap between opening and closure, fixation and mobility, i.e., creation and destruction of boundaries.
\end{abstract}

Key words: boundary; frontier; space; time.

E

m plena era dita de globalização difundiu-se amplamente, sobretudo nos países centrais, a ideia de um mundo cada vez mais reticulado e fluido. Produto e ao mesmo tempo condição para sua reprodução, as relações de produção capitalistas, especialmente sob o padrão neoliberal, promoveram práticas e discursos da fluidez, a "aniquilação do espaço pelo tempo" apregoada ainda no século XIX pelo crítico-mor do capitalismo, Karl Marx. Nas palavras de David Harvey, "a perpétua redução de barreiras espaciais é vital para o desenvolvimento capitalista da acumulação" (1994, p. 130) que, para Deleuze e Guattari, dá a impressão de que seus fluxos "se dirigiriam de boa-vontade para a lua, se o Estado capitalista não estivesse lá para os reconduzir à terra" (s/d[1972], p. 269).

Por outro lado, parecemos viver hoje um grande paradoxo: ao mesmo tempo em que se difunde essa imagem de um mundo sem fronteiras (pelo menos, ainda que de forma relativa, para 0 capital financeiro) nunca se construíram tantos muros como nos últimos quinze anos, inclusive entre fronteiras internacionais. Especialmente se olharmos a partir da periferia mundial, talvez nunca tenhamos nos envolvido com um rol tão diversificado e complexo de barreiras ou limites, desde fronteiras muradas de centenas de quilômetros até redutos mais cotidianos, como edifícios e casas cercados, passando por bairros onde o acesso, se não completamente vedado, é cada vez mais seletivamente controlado. 
Recentemente, em visita a um projeto social em favela da zona norte do Rio de Janeiro, fomos obrigados a atravessar uma barreira construída por uma facção do narcotráfico, composta por dois largos marcos de cimento cuja distância mal permitia a passagem de um carro, e cuja função, além de demarcar território (e, consequentemente, manifestar poder) de um grupo, é impedir a circulação de veículos maiores, como o "caveirão" da polícia militar. Em outras favelas, milícias se utilizam de táticas semelhantes. Por vezes a própria polícia das chamadas Unidades de Polícia Pacificadora (UPPs) nas favelas do Rio impõe não apenas um controle espacial mas também temporal, proibindo os moradores de saírem à rua a partir de um determinado horário.

O toque de recolher pode ser visto, em primeiro lugar, como uma medida autoritária formal que se revelou uma prática não apenas de muitos traficantes e milicianos, mas também de alguns policiais, e que deu origem a movimentos de resistência organizados como o Ocupa Borel e o Ocupa Alemão (este de atuação continuada, na luta contra a violência policial nas favelas, especialmente contra a população negra). Na verdade, para a vida cotidiana nas favelas de muitas periferias latino-americanas, trata-se, na prática, sem imposição mais formal, de uma espécie de "toque de recolher" cotidiano que, variável com a condição socioeconômica, de gênero e a faixa etária, obriga grande parte da população a restringir brutalmente sua mobilidade e, tantas vezes, "enclausurar-se" num pretenso espaço privado ou "doméstico", não raro violado por criminosos ou pela própria polícia.

Imposto de cima para baixo, de modo mais formal, ou inserido na vida cotidiana como um instrumento de sobrevivência (estabelecido por pais em relação a filhos, por exemplo, precavendo-se da violência), o toque de recolher, em sentido amplo, é um dispositivo de poder que alia de tal forma tempo e espaço que pode ser tomado como um primeiro exemplo, a servir de inspiração para a discussão teórica subsequente, sobre a relação espaço-tempo e a questão dos limites. Partirei do pressuposto, aparentemente banal, de que controlar e delimitar o espaço implica também, de alguma forma, controlar e impor limites ao tempo.

Como se estivéssemos imersos em distintos "toques de recolher" envolvidos no que Doreen Massey denominou múltiplas geometrias de poder e que Yves Lacoste denominou espacialidades diferenciais, mais do que um espaço da mobilidade e fluidez, vivemos hoje um mundo de fluxos altamente seletivos e de controles temporários, moldados por diversos interesses de ordem não apenas econômica mas também política e cultural - sem falar nas modulações, cada vez mais requisitadas, que se referem aos fluxos "ambientais" em sentido mais estrito (águas, ventos, dejetos etc.). É desse modo que o debate geográfico contemporâneo exige, cada vez mais, uma espécie de releitura do que entendemos por limites e/ou fronteiras territoriais.

Em trabalhos anteriores (HAESBAERT, 2004, 2014), tentei realizar um balanço das noções correntes e fortalecer uma leitura renovada do território, visto sempre numa perspectiva dinâmica, dentro do processo, concomitante, mas desigual, de (re)territorialização e desterritorialização. Inspirado em autores como Deleuze e Guattari (especialmente em suas obras "O Anti-Édipo" e "Mil Platôs") e Raffestin (por sua vez referendado em Foucault), defendi uma abordagem sobre o território que decorre de uma concepção também revista da relação espaço-tempo. Não havia conseguido, contudo, deter-me com mais ênfase neste que é um dos elementos mais importantes do território, o limite e/ou a fronteira. É este debate que será aqui retomado. 


\section{Sobre Espaço e Tempo}

O toque de recolher é um bom exemplo a evidenciar que a imposição de uma temporalidade - um horário - deve também vir acompanhada de uma restrição espacial - neste caso, de constrangimento à circulação. É praticamente impossível definir uma limitação temporal que não venha acompanhada da definição de uma circunscrição espacial de balizamento. Delimitar o tempo é, concomitantemente, uma forma de delimitar também o espaço, e vice-versa. Isso lembra, de saída, o grande debate geográfico-histórico que alia regionalização e periodização, tão bem explicitado pelo geógrafo francês Christian Grataloup em seus artigos complementares "As regiões do tempo" e "Os períodos do espaço" (GRATALOUP, 1991 e 2003).

Para Grataloup, cada conjunto de recortes regionais - ou, se quisermos, de delimitações espaciais - que reconhecemos e/ou que propomos, isto é, cada processo de regionalização, tem uma determinada duração temporal, ou seja, tem sua validade restrita a um determinado período de tempo, durante o qual a geografia se mantêm mais ou menos estabilizada. O mesmo ocorre para os recortes temporais do historiador: suas periodizações sempre estão, obrigatoriamente, referidas a um determinado contexto espacial, a um recorte regional. Por ignorarem as especificidades geográficas de cada região do mundo é que muitos historiadores eurocentrados extrapolaram, "exportando" uma periodização claramente europeia (principalmente a que distingue as eras: Idade Antiga, Média, Moderna e Contemporânea) para todos os cantos do mundo. Em síntese, "para cada área (ou região), uma era (ou período)".

Recortar o espaço e o tempo significa, de uma forma ou de outra, delimitar, concreta e/ou abstratamente, nosso espaço-tempo - em outras palavras e de modo bastante genérico, regionalizar e periodizar. Espaço e tempo são vistos aqui como categorias gêmeas, na perspectiva defendida por diversos geógrafos, entre os quais destacamos David Harvey e Doreen Massey. Ambos trabalham com uma perspectiva que rompe com a dicotomia que, durante muito tempo, separou espaço de tempo, o primeiro visto como fixação, estabilidade ou mesmo como "essência duradoura", "ser", e o segundo como mudança, dinâmica ou "devir". Como afirmou Michel Foucault (1979, p. 159), o espaço era tratado como "o que estava morto, fixo, não dialético, imóvel" frente a um tempo tido como "rico, fecundo, vivo, dialético".

Michel Foucault, sempre lembrado quando se fala dessa mudança de uma perspectiva dominantemente temporal para uma perspectiva de preponderância espacial, afirma que passamos da "grande obsessão" pela história, no século XIX, para uma época que "talvez seja a época do espaço". A emergência do espaço com tamanha força dar-se-ia porque estaríamos vivendo agora a "época da simultaneidade", da "justaposição", "do perto e do distante, do lado a lado, do disperso" (FOUCAULT, 1986, p. 22). Ainda que se ressalte a questão de que a modernidade privilegiou o tempo sobre o espaço (sobretudo através da ideia de um tempo linear e cumulativo de "progresso"), a questão crucial, segundo Grossberg (1996), é o tratamento separado do espaço e do tempo - inclusive através de nomenclaturas como "estrutura", mais estável e fixa, e "processo", responsável pela dinâmica e a transformação. Foi nesse sentido, por exemplo, que o historiador Fernand Braudel, em sua grande e louvável ênfase à fundamentação geográfica na história, chegou em determinado momento de seu estruturalismo a posicionar o espaço geográfico - apropriado por ele como "tempo geográfico", de longa duração - como o componente "da fixação" e mesmo 
do "retardamento" dos processos históricos, como se a geografia pudesse ser localizada numa temporalidade específica, quase única.

Os debates dos geógrafos anteriormente citados se reportam, direta ou indiretamente, a uma ampla linha de filósofos que se desdobra desde Leibniz, passando por Newton, Kant, Heidegger e Merleau-Ponty. Cada um a seu modo, através de determinado posicionamento filosófico, (re)define espaço em sua maior ou menor imbricação com o tempo - ou melhor, com a dimensão temporal da realidade. ${ }^{1}$ Vistos como "dimensões" do social, espaço e tempo não se reduzem a categorias analíticas, mas são vistos como constituintes das próprias práticas sociais (ou "percepções", para os fenomenologistas). Como afirmou Merleau-Ponty:

[...] a coexistência, que com efeito define o espaço, não é alheia ao tempo, ela é a pertença de dois fenômenos à mesma vaga temporal. Quanto à relação entre o objeto percebido e minha percepção, ela não os liga no espaço e fora do tempo: eles são contemporâneos. A "ordem dos coexistentes" não pode ser separada da "ordem dos sucessivos", ou antes o tempo não é apenas a consciência de uma sucessão. A percepção me dá um "campo de presença" no sentido amplo, que se estende segundo duas dimensões: a dimensão aqui-ali e a dimensão passadopresente-futuro. A segunda permite compreender a primeira. [de modo mais amplo, uma permite compreender a outra, eu diria] (MERLEAU-PONTY, 1999[1945], p. 357, destaque do autor)

Enquanto alguns fenomenologistas ressaltam o espaço como percepção subjetiva e/ou enfatizam sua dimensão corporal, individual, para um materialista como David Harvey, espaço e tempo são, antes de tudo, construções sociais (HARVEY, 1994). Inspirado em Henri Lefebvre (e também em Durkheim), ele assinala que não se trata de uma proposição especificamente geográfica, mas que se projeta amplamente por outras ciências sociais. "Dizer que algo é socialmente construído", diz Harvey, "não significa que é subjetivo e arbitrário", e "a determinação do que é espaço e do que é tempo não é politicamente neutra, mas está politicamente imbricada numa certa estrutura de relações de poder" (HARVEY, 1994, p. 127). Por outro lado, é muito importante destacar, cada cultura elabora sua própria concepção de tempo e espaço e com ela, de algum modo, "se move". Mesmo dentro de uma sociedade capitalista como a nossa Harvey irá reconhecer noções diferentes, por exemplo, entre o espaço-tempo do industrial e do investidor no mercado financeiro. Espaço e tempo são também "generificados", distinguem-se conforme o gênero a que estão referidos, pois homens e mulheres acabam de uma forma ou de outra construindo suas próprias espaço-temporalidades.

Muito mais do que um conjunto abstrato de linhas (ou um "contêiner" vazio a ser preenchido), um mero jogo de localizações de pontos ou delimitação de áreas, o espaço deve ser visto a partir de seu aspecto dinâmico e de suas distintas durações e, como diria Harvey $(1994,2012)$, de seu caráter relacional. Trata-se de um conjunto de relações que não apenas revela conexões "entre" espaços - ressaltadas na condição de espaço relativo - mas uma imbricação intrínseca à própria configuração desses espaços - a relação como constituinte inerente à espacialidade. Segundo Harvey, reunindo elementos do idealismo de Leibniz e do realismo de Whitehead, numa abordagem relacional "cada processo produz seu próprio espaço e tempo" (1994, p. 129), e a questão básica, ao contrário do espaço absoluto, é que espaço e tempo não podem ter existência inde-

\footnotetext{
${ }^{1}$ Para uma análise ainda mais abrangente dessa "história filosófica" da categoria espaço, ver o trabalho de Cassey (1997) que, embora utilize mais o termo "lugar" ("place") do que espaço, aborda desde as perspectivas espaciais de Platão e Aristóteles até as de Bachelard, Foucault, Deleuze e Guattari, Derrida e Irigaray.
} 
pendente, separada dos processos que os produzem. Harvey chega então à especificidade do espaço-tempo capitalista, indicando que o capitalismo revolucionou o espaço e o tempo ao redefini-los constantemente de acordo com suas novas exigências e necessidades.

Assim, aquilo que numa geometria mais simples, euclidiana, é lido como espaço-ponto, transforma-se automaticamente em espaço-conexão, as linhas são recheadas por fluxos e até mesmo as extensões ou zonas não só são constituídas por (ou "contêm") redes em movimento como também, em conjunto, movimentam-se - como na metáfora da mancha de óleo ou na realidade de uma massa de ar - que se desloca e se transforma. O espaço, assim, torna-se sobretudo fruto de conexões e, além disso, incorpora de forma indissociável o jogo entre os mundos material e mental, superando outra dicotomia que vê o espaço apenas como materialidade, "exterior", e o tempo como incorpóreo, "interior".

Mais do que a estabilidade de um "ser", o espaço envolve o constante "tornar-se" (outro). Desse modo, inspirado nos filósofos Deleuze e Guattari, Lawrence Grossberg (1993, p. 181) afirma:

É uma questão de geografia de devires ["becomings"], uma pragmática do múltiplo. (...) Devir é a espacialização da transformação; ele se recusa, não somente a privilegiar o tempo, mas a separar espaço e tempo. É uma questão de temporalizar o espaço e de espacializar o tempo. (...) Deleuze e Guattari tomam a realidade como sendo tanto real (produtiva) quanto contingente (produzida) - realidade produzindo realidade - e a produção da realidade é a prática do poder. Realidade não é nada senão efeitos que podem ser medidos somente como linhas, não pontos. ${ }^{2}$

Doreen Massey (2008) contribui decisivamente para essa releitura ao propor o espaço como um conjunto ou um emaranhado de trajetórias - ou, melhor ainda, de histórias, impregnando o espaço da densidade temporal que o compõe. Densidade temporal que não se reduz à materialidade relativamente fixa ("histórias enterradas", ela dirá) de uma "acumulação desigual de tempos" - nos termos de Milton Santos (1996) - mas se expande no sentido de uma dinâmica temporal que está constantemente sendo remodelada e reconstruída pelas múltiplas passagens que não apenas "cruzam" o espaço, mas, continuamente, o refazem.

\section{Sobre Limites e Fronteiras}

De uma forma ou de outra, variável conforme cada momento histórico e cada contexto geográfico, acabamos sempre estabelecendo algum tipo de limite, de fronteira - entre grupos, classes, indivíduos. É bem conhecido o amplo debate, travado sobretudo na área da Geografia Política, sobre limites e fronteiras. Machado (1998) nos lembra que fronteira, cuja etimologia sugere "o que está na frente", na origem não estava relacionada ao conceito legal ou político-administrativo a que hoje aparece predominantemente associada. A fronteira, desse modo,

\footnotetext{
${ }^{2}$ No original: "It is a matter of a geography of becomings, a pragmatics of the multiple". (...) "Becoming is the spatialisation of transformation; it refuses, not only to privilege time, but to separate space and time. It is a matter of the timing of space and the spacing of time. (...) Deleuze and Guattari take reality to be both real (productive) and contingent (produced) - reality producing reality - and the production of reality is the practice of power. Reality is nothing but effects which can be measured only as lines, not points".
} 
[...] nasceu como um fenômeno da vida social espontânea, indicando a margem do mundo habitado. Na medida que os padrões de civilização foram se desenvolvendo acima do nível de subsistência, as fronteiras entre ecúmenos tornaram-se lugares de comunicação e, por conseguinte, adquiriram um caráter político. Mesmo assim, não tinha a conotação de área ou zona que marcasse o limite definido ou fim de uma unidade política. Na realidade, o sentido de fronteira era não de fim, mas de começo do estado, o lugar para onde ele tendia a se expandir (p. 41, destaque da autora).

Assim, aparece hoje a conotação de "fronteira socioeconômica" ou mesmo "de povoamento", como fica claro pelo menos desde o clássico trabalho de Frederick Turner sobre a fronteira norte-americana (TURNER, 2004[1893]). Para Turner, a própria fronteira norte-americana - em sua interpretação, uma fronteira "da civilização" - constituiu a grande referência para a construção da nacionalidade dos Estados Unidos. ${ }^{3}$ Deleuze e Guattari (s/d[1972]) irão se referir ao "sentido americano" de fronteira como "algo a superar, limites para franquear, fluxos para fazer passar, espaços não codificados para penetrar" (p. 232), típico do processo de desterritorialização inerente à reprodução capitalista.

O geógrafo Porto-Gonçalves (2002, p. 351-352), por sua vez, destaca uma analogia interessante da fronteira como "front", lócus de lutas e disputas, tanto no sentido interno quanto em relação ao exterior:

As fronteiras comportam o front e trazem consigo, sempre, a memória das lutas que as engendraram. Portanto, mais do que o espaço absoluto dos territórios soberanos dos Estados modernos [e suas linhas limítrofes rígidas] destacamos seu caráter aberto (poroso) e contraditório, tanto no front interno quanto no front externo. Há, sempre, por trás do instituído o processo instituinte e, no caso da fronteira, o limite explicita o seu caráter essencialmente político.

O limite, em relação à fronteira, tem uma conotação política mais explícita. Quando lembramos sua origem romana, nos "limes" que delimitavam o alcance dos domínios do Império, muitas vezes fixados por muros, fica muito claro seu papel definidor de um "fim" político-administrativo. Machado (1998, p. 42) ressalta essa distinção entre limite e fronteira:

A fronteira está orientada para fora (forças centrífugas), enquanto os limites estão voltados para dentro (forças centrípetas). Enquanto a fronteira é considerada uma fonte de perigo ou ameaça porque pode desenvolver interesses distintos aos do governo central, o limite jurídico do Estado é criado e mantido pelo governo central, não tendo vida própria e nem mesmo existência material, é um polígono.

Hissa (2002, p. 20 e 21), por sua vez, associa o limite, mesmo na natureza, a uma abstração:

[...] o conceito de limite é próprio da cultura dos povos. A natureza física, assim definida pelos "olhos da cultura", não estabelece guardiões de fronteiras e tampouco estabelece limites de forma deliberada. Na natureza, o limite é um elemento intruso, idealizado. (...) tudo o que pode ser compreendido como próprio dos domínios da natureza desconhece o limite e a sua própria existência.

Para esse autor, a fronteira também é feita de um "espaço abstrato", porém areal, "por onde passa o limite" (HISSA, 2002, p. 34). Fronteira, geograficamente falando, envolve sempre, portanto, uma área ou zona (o que torna o termo "zona de fronteira" um tanto redundante), e parece in-

\footnotetext{
${ }^{3}$ Para uma análise comparativa entre a formação territorial brasileira e a norte-americana, a partir dessa ideia de "fronteira (socioeconômica) em movimento", ver o trabalho do antropólogo Otávio Velho (1979).
} 
dicar mais um começo, enquanto o limite é representado por uma linha e "parece significar o fim do que estabelece a coesão do território" (HISSA, 2002, p. 34). Isso não significa, entretanto, que não seja amplo o debate em torno de sua interseção, até por que, no senso comum, seu uso como sinônimos é bastante difundido. Ainda que o limite estimule "a ideia sobre a distância e a separação" e a fronteira incite a pensar "sobre o contato e a integração", a distinção entre os conceitos envolve um "espaço vago e abstrato" (HISSA, 2002, p. 34).

Limites, de qualquer modo, são componentes indissociáveis das fronteiras, especialmente quando estas são definidas priorizando-se sua conotação política. ${ }^{4}$ Se o limite trabalha obrigatoriamente com alguma ideia de fixação, a fronteira envolve, sobretudo, a concepção de movimento e transformação do espaço. Num mundo mais móvel como o nosso, hoje, é claro que essas distinções, como veremos logo adiante, devem ser problematizadas.

O sociólogo José de Souza Martins enfatizou a perspectiva conflitiva e espaçotemporalmente situada da fronteira em seu livro "Fronteira: a degradação do Outro nos confins do humano", questionando a visão idealizada da fronteira como "frente pioneira" onde o colonizador é visto como "suposto herói criador", modernizador e transformador da sociedade. Assim, afirma o autor:

[...] o aparentemente novo da fronteira é, na verdade, expressão de uma complicada combinação de tempos históricos em processos sociais que recriam formas arcaicas de dominação e formas arcaicas de reprodução ampliada do capital, inclusive a escravidão, bases da violência que a caracteriza. [...] As concepções centradas na figura imaginária do pioneiro deixam de lado o essencial, o aspecto trágico da fronteira, que se expressa na mortal conflitividade que a caracteriza, no genocida desencontro de etnias e no radical conflito de classes sociais [...]. (MARTINS, 1997, p. 15)

Se a fronteira pode representar uma espécie de dianteira que nos impulsiona para a frente, no rumo do novo, convocando-nos a transpor limites, nada garante que esse novo e que essa transposição seja apenas ou sobretudo positiva. Ao invés de apenas "frente" ou "início", ela inclui também um fim - ou, pelo menos, um "com-fim" onde o mesmo e o Outro acabam, inexoravelmente, se encontrando - ou se desencontrando, como destaca Martins. É nesse duplo sentido de "front", enquanto espaço de luta, do avanço e da inovação e ao mesmo tempo da contenção, da retenção e da permanência - e, assim, também do conflito, como enfatiza Martins - que encontramos a "verdadeira" fronteira - e os limites da fronteira.

Percebe-se agora o quanto o debate sobre limites e fronteiras tem a ver com a questão mais ampla do próprio espaço e sua relação indissociável com o tempo. Olhar o limite é olhar também para as limitações de nossas concepções de espaço. Diante do limite como linha e fixação, voltados para um "dentro" precisamente definido, corremos o sério risco de permanecer numa visão muito restrita de espaço absoluto, de uma coexistência sem fluxo, estática, onde cada espaço que o limite separa é enfatizado em suas propriedades independentes, como se cada território - estatal, por exemplo - pudesse ser lido apenas por suas singularidades (geográficas, linguísticas, étnicas...), esquecendo-se que com frequência são esses próprios limites, a princípio abstratos, que forjam essas especificidades. Mais do que a estabilidade de um "ser", o limite pode ser visto, antes de tudo, pela transformação de um constante "vir-a-ser". Nos termos de Hissa (2002):

\footnotetext{
${ }^{4}$ Sobre as diferentes conotações de fronteira política no pensamento geográfico, ver Cataia (2010).
} 
O limite almeja a precisão e se insinua como muro, mas contraditoriamente, através da fronteira, apresenta-se como transição, como mundo do permanente vir-aser e da ausência pulsante. Nesses termos, como pensar a fronteira como demarcação entre domínios? (p. 35)

O filósofo Heidegger destaca no "limite" não o seu caráter de fim, onde algo termina, mas, "como haviam observado os gregos, aquilo a partir do qual alguma coisa começa a ser (sein Wesen beginnt)". Por outro lado, o próprio espaço, dirá ele, "é essencialmente o que foi 'arranjado' ['arrumado'], o que se faz entrar no seu limite". (HEIDEGGER, 2006 [1954], p. 183). ${ }^{5}$ Essas constatações trazem à tona o caráter espacial ambíguo do limite: ao mesmo tempo em que indica menos um término e mais uma emergência, um "vir-a-ser", ele demonstra que todo arranjo do espaço - ou, como preferimos, toda des-articulação (com hífen) espacial - implica alguma forma de ordenamento, de ordem espacial, por mais precária ou desarticulada que pareça.

Limite, portanto, não pode ser visto apenas como marcação de diferenças e apartação, controle da mobilidade e segregação. Quando Hissa (2002) afirma que "talvez o significado mais decisivo de limite seja o que imediatamente conduz à ideia de cerceamento da liberdade", proposto como "obstáculo ao trânsito livre", aquilo que "se põe a vigiar o território e o domínio proibidos", despertando "a noção de propriedade" (p. 19), devemos tomar cuidado para não incorrer no equívoco de ver limite num sentido estrita e exclusivamente negativo. Até porque, num sentido amplo, nossa vida pode ser vista como desdobrando-se num ir-e-vir entre aberturas e fechamentos, fixações e mobilidades - em outras palavras, criação e destruição de limites. Como se trata de dimensões geminadas, "fechamento" e "fixação" serão sempre, é claro, relativos. Ou, mais ainda, relacionais, pois a relação mútua não apenas deve ser reconhecida entre esses processos, mas também na constituição interna de suas produções, dos arranjos espaciais daí advindos.

\section{Sobre Limites no Espaço-Tempo contemporâneo}

Hoje, mais do que em outros tempos, com o avanço tecnológico e as mudanças políticoeconômicas que aceleraram fluxos de toda ordem - criando toda uma geometria espacial de poder complexa e desigual, veio à tona, com muito mais força, a discussão dos "limites" - limites como restrição, contenção, numa conotação negativa, mas também no sentido de constituírem parte indissociável de nossa dinâmica civilizatória, na medida em que, biopoliticamente falando, o modelo societário hegemônico, baseado na acumulação e/ou no "crescimento" capitalista, colocou em jogo até mesmo nossa sobrevivência enquanto espécie biológica sobre a Terra.

Não se trata, contudo, da ilusão modernista de limites e segmentações espaciais claras, como ocorria nas sociedades disciplinares clássicas através do mito da individualização funcional dos espaços que a tudo/a todos deveria ordenar. As sociedades atuais, mesmo que dificilmente possam ser caracterizadas de modo genérico, são vistas como "sociedades de controle" - no sentido de controle como "verificação" (DELEUZE, 1992) - ou como "sociedades de segurança" (FOUCAULT, 2008). Não há dúvida, entretanto, que a insegurança se transformou num "modo de

\footnotetext{
${ }^{5} \mathrm{Na}$ tradução francesa: "comme les Grecs l'avaient observé, ce à partir de quoi quelque chose commence à être (sein Wesen beginnt)"; "est essentiellement ce qui a été 'ménagé', ce que l'on a fait entrer dans sa limite". (grifos no original).
} 
gestão da vida coletiva" (RANCIÈRE, 2003) e que o capitalismo se manifesta igualmente como um "capitalismo de desastre", gerenciador de crises (KLEIN, 2008). A crise, que Milton Santos já identificava como definidora, ela própria, de uma era e não mais como uma transição entre períodos, é vista hoje como condição a ser "administrada", inerente que seria à nossa reprodução enquanto sociedade, e não como uma situação a ser efetivamente combatida. Nas palavras de Giorgio Agamben (2013), "[...] não apenas na economia e na política, mas em todos os aspectos da vida social, a crise coincide com a normalidade e torna-se, deste modo, apenas uma ferramenta de governo".

Agamben, reportando-se a Foucault quando este localiza a ideia moderna de segurança nas propostas de Quesnay durante o "Ancien Régime", afirma que o "axioma da governamentalidade moderna" se torna a máxima "já que governar as causas é difícil e caro, é mais seguro e útil tentar governar os efeitos" (2013, versão on line). A grande meta da política contemporânea é, portanto, controlar os efeitos, ao invés de atacar e dominar as causas. Com isso é possível evidenciar a correspondência contraditória entre "um paradigma econômico absolutamente liberal" e "um paradigma de controle policial e estatal sem precedentes e igualmente absoluto". Isso, na verdade, ajuda-nos a compreender o paradoxo indicado no início deste texto, entre um mundo de ruptura de limites e fronteiras para frações do grande capital e restaurador de barreiras e controles fronteiriços, especialmente no "Estado policial" instaurado para vigiar refugiados e migrantes pobres. Assim, "se o governo aponta para os efeitos e não para as causas, será obrigado a estender e a multiplicar o controle [verificação e cálculo de "riscos", de probabilidades]. As causas exigem ser conhecidas, enquanto os efeitos apenas podem ser verificados e controlados". (AGAMBEN, 2013, versão on line)

Foucault (2008) nos adverte para o fato de que, nas sociedades de segurança - também denominadas de sociedades biopolíticas ${ }^{6}$ - a grande questão é o controle do que ele denomina "meio", o espaço em que se dá a circulação. A mobilidade, os fluxos, em suas distintas modalidades, tanto de elementos humanos quanto não-humanos, torna-se um objeto central da política. ${ }^{7}$ Assim, ao contrário dos limites espaciais mais rígidos e fechados propostos pela reclusão disciplinar, temos o que denominei de processos de contenção territorial (HAESBAERT, 2014), mais dinâmicos e ambíguos, onde acaba prevalecendo um efeito "barragem" e/ou de "canalização", muito mais do que de reclusão (fechamento por todos os lados). Foucault fala de um processo seletivo de mobilidade, separando e monitorando as "boas" e "más" circulações. Assim, podemos afirmar:

Nosso tempo, [...] longe de ser um tempo "sem limites" - que seria, em última instância, um "tempo sem espaço", destituído de todo território e fronteira -, é um mundo que, talvez, acolha a maior diversidade de manifestações territoriais já conhecida na história humana e, contraditoriamente, o que vive o maior risco de perda dessa diversidade. Daí a frequência com que se refazem limites, se reconstroem fronteiras, mas geralmente em benefício dos padrões impostos e/ou defendidos pelos grupos hegemônicos e envolvendo disputas internas a frações da classe dominante. Joga-se o tempo todo com (noss)os limites, tanto no sentido de redefinir linhas e zonas demarcatórias quanto de redirecionar, acelerando ou retardando fluxos. (HAESBAERT, 2014, p. 299)

Agamben ressalta que, hoje, o próprio Estado securitário, submetido "ao signo da seguran-

\footnotetext{
${ }^{6}$ Para o debate sobre o que denomino "sociedades biopolíticas de in-segurança" e o "des-controle dos territórios" aí envolvido, ver Haesbaert, 2014, especialmente o capítulo 6.

${ }^{7}$ Para o debate sobre mobilidade na Geografia, ver Creswell (2006).
} 
ça" e abandonando o domínio da política, "entrou numa terra de ninguém, cuja geografia e fronteiras são ainda desconhecidas". Isso gera uma preocupação extrema "sobre os perigos que representa para a democracia, porque nele se tornou impossível a vida política, e democracia significa precisamente a possibilidade de uma vida política". Em mais de um sentido, relembrando PortoGonçalves (2002) ao se reportar à polis como "limite" e à política como "arte de definir limites" (p. $300)^{8}$, é por perder seu(s) limite(s) que o Estado - e, com ele, de certa forma, a própria política acaba se esvaziando, inclusive no sentido de construção e/ou manutenção do chamado espaço público ou, de forma mais ampla, dos espaços do bem comum.

Não se trata mais, contudo, de privilegiar os (des)ordenamentos territoriais zonais, o controle da população pelo controle de áreas bem delimitadas, processo inerente à reprodução do Estado-nação, que expandiu pelo mundo todo a sua imensa colcha de retalhos de pretenso poder exclusivo sobre parcelas territoriais não sobrepostas e, preferencialmente, contínuas. Os "limites" territoriais, hoje, se dão também pelo controle de redes, de circuitos de mobilidade, de rotas de circulação, em sentido estrito. Se seguirmos a afirmação de Deleuze e Guattari (1996) de que também nos territorializamos pela repetição do movimento, o comando de movimentos ou fluxos se torna uma das formas cada vez mais evidentes de controle territorial. O controle da acessibilidade enfatizado por Robert Sack (1986) em sua definição de territorialidade produzindo territórioszona deve ser ampliada para o controle do acesso não apenas a áreas, mas também a redes, vias ou circuitos de mobilidade.

E como, para além da definição de delimitações zonais, controla-se uma rede? Pode-se afirmar que esse controle se evidencia sob duas formas principais:

a) o estabelecimento de "barragens" ou barreiras, com ou sem monitoramento por câmeras e/ou "checkpoints"; por nunca envolverem todas as passagens, essas barreiras acabam deixando sempre a possibilidade de serem contornadas, mais vertical (via satélites e "drones", por exemplo) ou mais horizontalmente (via muros e/ou torres de controle em linhas de fronteira); ${ }^{9}$

b) a "canalização" de eixos ou circuitos de circulação - que pode se dar tanto de forma mais concreta com grandes vias elevadas ou muros-dutos, como aqueles que protegem grandes artérias de tráfego (como a Linha Vermelha, no Rio de Janeiro), quanto de forma menos material, pelo monitoramento da mobilidade pelo uso de câmeras em espaço aberto ou, de forma mais direta, por meio de dados biométricos ou tornozeleiras eletrônicas.

Podemos aqui retomar o exemplo de algumas favelas do Rio de Janeiro, bastante elucidativo da ambivalência dos "limites" - sejam eles mais zonais ou mais reticulares, no controle espacial de fluxos de diversas ordens. A política das UPPS - Unidades de Polícia Pacificadora - publicizada pelo Estado como a grande saída para a questão da violência associada ao narcotráfico nas favelas cariocas tem representado, efetivamente, a consolidação de um Estado de exceção (AGAMBEN, 2004), policial ou militarizado cuja intervenção, proposta como temporária, acaba por

\footnotetext{
${ }^{8}$ Limites que, segundo o autor, são definidos por um - para todos - na tirania, por poucos, na oligarquia, e por todos para todos os cidadãos - na democracia. "Assim, para os gregos, pólis e política se pressupõem, assim como cidade e cidadania" (PORTO-GONÇALVES, 2002:300).

${ }^{9}$ É interessante verificar como essas tecnologias se complementam. Chamayou (2015), reportando-se ao controle "teleárquico" (comando a distância ou telecomando sem cabo, como definido por Burnet Hershey), afirma que "o drone e o muro funcionam juntos. Articulam-se de forma coerente em um modelo de segurança que combina fechamento do espaço doméstico e intervenção externa desprovida de qualquer envolvimento vital. O ideal da força telecomandada é perfeitamente congruente com o de um Estado-bolha". (p. 252).
} 
se tornar permanente. Diversos acontecimentos recentes colocam em xeque a eficácia desse modelo autoritário e totalizante - totalizante tanto no sentido mais "vertical", da ação hierárquica da polícia que, como nos toques de recolher já aqui comentados, extrapola em muito as suas atribuições formais, quanto no sentido mais "horizontal" que, na ausência de políticas sociais efetivas que acompanhem o processo de característica militar, insere a polícia em áreas e questões sociais muito além das atribuições estritas a que está delegada.

Numa clara confirmação da máxima de Agamben (2013) de que a sociedade ("de segurança") contemporânea desistiu "de qualquer tentativa de dominar as causas" e se dedica apenas a "governar os efeitos", o próprio secretário de Segurança do estado do Rio de Janeiro, José Beltrame, diante dos efeitos mitigados da política "de ocupação" das favelas reconhece que o objetivo não era acabar com o narcotráfico, mas "retomar seus territórios". Ele só esquece de reconhecer que se trata de um tipo muito particular de território, o território-zona, cujo domínio, cada vez mais dispendioso, pela necessidade de manter um aparato militarizado, já era questionado pelo próprio narcotráfico. Assim, proliferam os territórios-rede onde o domínio de pontos, ou melhor, de conexões estratégicas, especialmente para a comercialização da droga, é a condição mais relevante. Sem falar nos traficantes que se reterritorializaram "zonalmente" em áreas mais periféricas da cidade ou da região metropolitana, onde se acirram disputas por território entre diferentes facções.

O limite assim configurado não passa de uma "barreira de segurança" (ou "cinturão", como denominado pela própria Secretaria), bastante vulnerável em sua constituição, que não estabelece uma proteção definitiva, parecendo apenas postergar o problema ou relegá-lo a certas áreas da cidade. Esse "cinturão de segurança" privilegia as zonas sul e centro, assim como algumas áreas da zona oeste e Barra da Tijuca onde estarão localizados os eventos dos Jogos Olímpicos de 2016. Uma das questões sempre colocada pela população local é que tipo de prosseguimento terá o projeto após a realização dos Jogos e a crise econômica, com a redução dos vultosos recursos exigidos para sua manutenção e/ou expansão. Neste caso também verificamos o envolvimento do processo num espaço-tempo específico: até onde e até quando as UPPs atuarão - como mera política militarizada (sem uma real política social), como mera ocupação de áreas (sem controle efetivo das redes - locais, nacionais e internacionais - de drogas e de armas) e como simples paliativo ou protelatório de uma situação muito mais complexa abrangendo a ambiguidade dos limites entre os circuitos legais e ilegais da economia e do poder (tal como enfatiza TELLES, 2010).

É essa ambiguidade dos limites entre o legal e o ilegal que impregna hoje a própria constituição da política "normal" do Estado, que recorre ao que Agamben (2013) denomina "pequenos golpes de Estado", por apelar todo tempo a situações emergenciais que justifiquem a tomada de medidas e o estabelecimentos de uma "legalidade ilegal", excepcional. No caso específico das favelas do Rio de Janeiro esse desenho é ainda mais intrincado, com agentes "legais", como a polícia oficial do Estado, participando, ao mesmo tempo, de circuitos ilegais - não só ao ser corrompida pela admissão do "arrego" (pagamento) acordado com os traficantes, mas também pela atuação, direta, como uma espécie de "segurança privada", nas várias milícias que se estendem pelas periferias da cidade, em especial na zona oeste.

Isso faz com que grande parte da região metropolitana do Rio de Janeiro se encontre hoje numa espécie de ir-e-vir jurídico-político em que diversos sujeitos se sucedem ou se sobrepõem no controle territorial, de modo a constituir uma territorialidade muito complexa e quase "sem limi- 
tes", no sentido de admitir todo tipo de limite, consecutiva ou simultaneamente. Embora voláteis em termos de troca de facção criminosa, por exemplo - esses territórios mantêm, quase sempre, a violência e o constrangimento, ainda que temporário, à própria mobilidade da maioria de seus habitantes. Contudo, uma marca territorial muito explícita e relativamente constante é a imprevisibilidade e/ou a insegurança. Justamente por essas características é que não se trata, como admitido no senso comum, de "espaços fechados" ou "confinados". Longe disso, as favelas do Rio de Janeiro - como muitas periferias metropolitanas da América Latina - são marcadas por uma territorialidade múltipla que vai desde a presença mais explícita do Estado (através de unidades policiais e escolares, por exemplo) e do poder local do narcotráfico até redes globais de articulação de certos movimentos populares.

Apenas para finalizar com um exemplo muito concreto, um morador de uma das favelas mais afetadas pela violência na zona norte do Rio de Janeiro participa ou, em outras palavras, transita por uma multiterritorialidade que inclui: emprego em uma empresa pública do Estado do Rio de Janeiro (o que lhe exige circular cerca de 30 quilômetros diários para o trabalho na área central da cidade); participação em uma entidade ligada a movimentos populares que têm atuação ao mesmo tempo na própria favela e em vários estados do Brasil (o que, ocasionalmente, leva-o a viajar para outros estados); e relação (ainda que eventual) com representantes do poder local ligado a uma facção do narcotráfico (que, por sua vez, está articulada nacional e internacionalmente, através dos circuitos de armas e drogas).

Como se pode observar, muito mais do que limites espaço-temporalmente bem demarcados, vivemos hoje, principalmente nas periferias urbanas, uma sobreposição e imbricação de poderes de tal ordem que seria mais adequado falar de uma transterritorialidade - 0 trânsito frequente, compulsório ou voluntário, por distintas territorialidades. O reconhecimento da relevância desse trânsito levou-me a utilizar a expressão "viver no limite" (HAESBAERT, 2014). Aí, explorei a dupla conotação do termo:

[...] pois envolve o sentido contraditório de estar numa situação ao mesmo tempo de impulsionamento e excesso e de fragilidade e risco. Mas ímpeto para assumir riscos significa também desafio, antessala do novo - melhor ou pior, mas que implica buscar, arriscar. Numa perspectiva mais geográfica, já que a metáfora do limite/fronteira está sempre colocada, podemos afirmar que adquire outra dupla conotação: viver no limiar de um espaço, transpondo suas fronteiras - ou viver em e através delas - e viver refazendo, reconstruindo ou repondo limites, vistos concomitantemente como término e (re)começo. (HAESBAERT, 2014, p. 298-299)

Esse ir-e-vir entre diferentes territórios, ultrapassando limites, tem, obviamente, uma conotação que pode ser tanto positiva quanto negativa, pois quando compulsório reduz drasticamente o caráter libertário que potencialmente carrega. Estar em movimento e transitar por diversos territórios não é, portanto, sinônimo de maior autonomia e liberdade. Hannah Arendt (2004) chega mesmo a afirmar que (para o bem ou para o mal, acrescento), "os corpos políticos sempre foram projetados com vistas à permanência e suas leis sempre foram compreendidas como limitações impostas ao movimento" (p. 56). Essa constatação nos faz lembrar a distinção, muitas vezes necessária, entre o uso político ou normativo da categoria "limite", o uso pelo senso comum, envolvido em atividades práticas, cotidianas, e o uso analítico, às vezes questionado, como vimos no início deste artigo.

Diante das críticas a "limite" analiticamente reconhecido como linha demarcatória, que teria 
um caráter sempre arbitrário, Hissa dirá que se trata de "um conceito inventado para dar sentido às coisas, para facilitar a compreensão do que pode ser interpretado de diversas maneiras" (2002, p. 21). Raffestin, por seu lado, questiona de forma mais incisiva:

Não há nada mais absurdo que ouvir dizer que todo sistema de limites é arbitrário. Sem dúvida, todo sistema de limites é convencional, mas desde o momento em que foi pensado, colocado no lugar e que funcione, ele não é mais arbitrário, pois facilita o enquadramento de um projeto social, aquele mesmo de uma sociedade. (...) os limites só manifestam um projeto que por si mesmo não é arbitrário, pois isso seria admitir que a classe dominante não procura enquadrar seu projeto social e comunicá-lo sob uma forma ideológica (RAFFESTIN, 1993, pp. 165 e 166).

De qualquer modo, mesmo que condenemos linhas delimitadoras por não existirem exatamente como tais na realidade, jamais poderemos ignorar os diversos usos - inclusive ideológicos - que delas são feitos. Como afirmei em outro momento, "mais do que nos perguntarmos sobre a 'realidade' desses recortes [limites], devemos nos indagar para que servem - o que fazemos com eles - e/ou quais seus efeitos, especialmente políticos" (HAESBAERT, 2014, p. 121). ${ }^{10}$ Efeitos que estão profundamente impregnados de historicidade, pois "todo período de crise, toda insurreição, toda revolução se traduzem por modificações mais ou menos fortes nos sistemas de limites" (RAFFESTIN, 1993, p. 170). Para retomar conclusivamente o debate inicial sobre a relação entre limites e espaço-tempo, reproduzo outra proposição de Raffestin:

[...] o limite ou a fronteira não decorrem somente do espaço, mas também do tempo. De fato, a quadrícula não é exclusivamente territorial, é também temporal, pois as atividades que são regulamentadas, organizadas e controladas se exprimem de uma só vez, no espaço e no tempo, num local e num momento dados, sobre uma certa extensão e por uma certa duração (RAFFESTIN, 1993, p. 169).

Um claro exemplo de refuncionalização espaço-temporal de barreiras fronteiriças é o que ocorre hoje com diversos muros, mais antigos ou mais recentes, da muralha da China e do muro de Adriano (no norte da Inglaterra) aos muros entre as duas Coreias, muitos deles com um papel muito mais simbólico do que material. ${ }^{11}$ Concluo então por afirmar que o discurso do "fim" das fronteiras ou dos limites deve ser questionado não apenas pela ideologia neoliberal contemporânea que o legitima mas também porque a questão não envolve apenas as linhas demarcatórias e barreiras em si mesmas, mas, sobretudo, o sentido político, espaço-temporalmente diverso, desses limites - a quem e para que servem. Como argumentam von Houtum et al. (2005), lembrando Latour, a presença de uma chave na mão pode transformar uma porta numa simples passagem ou, ao contrário, numa barreira intransponível. Da mesma forma, um muro pode significar proteção para uns e um insulto ou uma provocação para outros.

Raffestin dirá que, "sendo 'convencionais", as divisões, classificações e/ou delimitações "nem sempre são satisfatórias do ponto de vista existencial" e é por isso que "toda mudança de malha [territorial] implica uma nova estrutura de poder" (1993, p. 170). Nesse sentido, se nossa luta é por territórios muito mais autônomos, e de liberdade, que deem conta de nossa existência

\footnotetext{
${ }^{10}$ Neste mesmo trabalho, de modo provocativo, foi feita uma breve releitura da linha limítrofe à luz da "metáforaconceito" da "dobra", no sentido proposto por Deleuze, para quem "o múltiplo é não só o que tem muitas partes, mas o que é dobrado de muitas maneiras" (apud HAESBAERT, 2014, p. 122). Ver o limite, mais do que como uma linha, como uma dobra, significa trabalhar ao mesmo tempo com as ideias de continuidade e descontinuidade espacial, tratando o espaço não como mera superfície bidimensional, mas como um composto denso de três dimensões (sem falar na "quarta", que é o tempo).

${ }^{11}$ Entre os diversos trabalhos recentes sobre o papel dos muros fronteiriços ver, por exemplo, Brown (2009) e Rosière (2015).
} 
em um sentido mais amplo, isso implica considerar não o fim dos limites e/ou das fronteiras, mas o estabelecimento de uma outra modalidade de malha territorial, de "territórios cujas demarcações, apesar de estabelecerem limites, distinções (reconhecendo nossa multiplicidade), permanecem suficientemente flexíveis para serem reavaliados, reconstruídos e recolocados sempre que uma nova configuração sociopolítica mais democrática e justa o demandar" (HAESBAERT, 2014, p. 298). Em outras palavras:

A luta concreta implica que cada grupo [...] tenha a capacidade, a autonomia e a liberdade para abrir ou fechar (em outras palavras, bem ou mal delimitar) seu território quando assim o julgar necessário. Talvez pudéssemos afirmar que o território [...] autônomo seria aquele em que temos efetivo poder para abri-lo e/ou fechá-lo quando assim, livremente, decidirmos, sem que isso afete negativamente a vida daqueles que estão a seu redor. (HAESBAERT, 2014, p. 123)

É através desse jogo ao mesmo tempo espacial e temporal dos limites, variável conforme a história e a geografia de cada grupo social, que se desenham as múltiplas possibilidades de construção de uma efetiva e múltipla autonomia territorial. Mas esse já é tema para outro, intenso, debate - que permaneça, então, a provocação para desdobramentos futuros. 
Referências

AGAMBEN, G. Por uma teoria da política instituinte. 2013. Disponível em: <http://www.revistapunkto.com/2015/05/por-uma-teoria-da-potencia-destituinte.html>. Acesso em: 20 dez. 2015.

. Estado de Exceção. São Paulo: Boitempo, 2004.

ARENDT, H. A Condição Humana. Rio de Janeiro: Forense Universitária, 2004.

BRAUDEL, F. O Mediterrâneo e o mundo mediterrânico na época de Felipe II. Lisboa: Martins Fontes, 1983 [1946].

BROWN, W. Murs: les murs de separation et le déclin de la souveraineté. Paris: Les Prairies Ordinaires, 2009.

CASSEY, E.S. The fate of place: a philosophical history. Berkeley e Los Angeles: California University Press, 1997.

CATAIA, M. Fronteiras: territórios em conflitos. Geografia em questão v.3, n.1, 2010. Disponível em: <http://e-revista.unioeste.br/index.php/geoemquestao/issue/view/350/showToc>.

CHAMAYOU, G. Teoria do Drone. São Paulo: Cosac Naify, 2015.

CRESWELL, T. On the move: mobility in the modern Western world. Nova York: Routledge, 2006.

DELEUZE, G. 'Post-Scriptum' sobre as sociedades de controle. Conversações. São Paulo: Ed. v.34, 1992 [1990].

DELEUZE, G.; GUATTARI, F. Mil Platôs. São Paulo: Ed. 34, 1996.

. O Anti-Édipo: capitalismo e esquizofrenia. Lisboa: Assírio \& Alvim, s/d [1972].

FOUCAULT, M. Segurança, território e população. São Paulo: Martins Fontes, 2008.

. Of other spaces, Diacritics v.16, n.1, 1986 [1967]. Ed. brasileira: "Outros espaços", in: Ditos e Escritos III: Estética - literatura e pintura, música e cinema. Rio de Janeiro: Forense Universitária, 2001).

. Microfísica do Poder. Rio de Janeiro: Graal, 1979.

GRATALOUP, C. Les périodes de l'espace. EspacesTemps v.82-83, 2003 (ed. brasileira: "Os períodos do espaço", GEOgraphia v.16, 2006).

. Les régions du temps. In: Périodes. La construction du temps historique. Paris: Ed. da EHESS et Histoire au Présent, 1991.

GROSSBERG, L. The space of culture, the power of space. In: CHAMBERS, I.; CURTI, L. (Ed.) The Post-Colonial Question: common skies, divided horizons. Londres e N. York: Routledge, 1996.

HAESBAERT, R. O mito da desterritorialização: do "fim dos territórios" à multiterritorialidade. Rio de Janeiro: Bertrand Brasil, 2004.

Viver no limite: território e multi/transterritorialidade em tempos de in-segurança e contenção. Rio de Janeiro: Bertrand Brasil, 2014. 
HARVEY, D. The social construction of space and time: a relational theory. Geographical Review of Japan v.67, n.2, 1994.

O espaço como palavra-chave. GEOgraphia v.14, n.28, 2012 [2006].

HEIDEGGER, M. Bâtir habiter penser. In; Essais et conférences. Paris: Gallimard, 2006 [1954].

HISSA, C. A mobilidade das fronteiras: inserções da geografia na crise contemporânea. Belo Horizonte: Ed. UFMG, 2002.

KLEIN, N. A doutrina do choque: a ascensão do capitalismo de catástrofe. Rio de Janeiro: Nova Fronteira, 2008.

LACOSTE, Y. A Geografia, isso serve, em primeiro lugar, para fazer a guerra. Campinas: Papirus, 1988 [1976].

MACHADO, L. Limites, fronteiras, redes. In: STROHAECKER, T. et al. (Org.). Fronteiras e Espaço Global. Porto Alegre: AGB, 1998.

MARTINS, J.S. Fronteira: a degradação do Outro nos confins do humano. São Paulo: Hucitec, 1997.

MASSEY, D. Pelo Espaço: por uma nova política da espacialidade. Rio de Janeiro: Bertrand Brasil, 2008 [2005].

Space, Place and Gender. Minneapolis: University of Minnesota Press, 1994.

MERLEAU-PONTY, M. Fenomenologia da percepção. São Paulo: Martins Fontes, 1999 [1945].

PORTO-GONÇALVES, C.W. Da geografia às geo-grafias: um mundo em busca de novas territorialidades. In: CECEÑA, A.; SADER, E. (Org.). A guerra infinita: hegemonia e terror mundial. Petrópolis: Vozes, Rio de Janeiro: LPP e Buenos Aires: Clacso, 2002.

RAFFESTIN, C. Por uma geografia do poder. São Paulo: Ática, 1993 [1980].

RANCIÈRE, J. O princípio da insegurança. Folha de São Paulo, 21 de setembro de 2003.

ROSIÈRE, S. Mundialização e teicopolíticas: análise do fechamento contemporâneo das fronteiras internacionais. Boletim Gaúcho de Geografia v.42, n.2, 2015.

SACK, R. Human territoriality. Cambridge: Cambridge University Press, 1986.

SANTOS, M. A natureza do espaço. Técnica e tempo, razão e emoção. São Paulo: Hucitec, 1996.

TELLES, V. A cidade nas fronteiras do legal e do ilegal. Belo Horizonte: Argvmentvm, 2010.

TURNER, F. O significado da fronteira na história americana. In: KNAUSS, P. (Org.). Oeste americano: quatro ensaios de história dos Estados Unidos da América. Niterói: EdUFF, 2004 [1893].

VELHO, O. Capitalismo autoritário e campesinato: um estudo comparativo a partir da fronteira em movimento, $2^{\mathrm{a}}$ ed. São Paulo: Difel, 1979.

Von HOUTUM, H.; KRAMSCH, O.; ZIERHOFER, W. Prologue. B/ordering space. Aldershot e Burlington: Ashgate, 2005. 